\title{
Integral Separation PID Control of Certain Electro-hydraulic Servo System based on RBF Neural Network Supervision
}

\author{
Ronglin WANG ${ }^{1, a}$, Baochun $\mathrm{LU}^{1, \mathrm{~b},{ }^{*}}$ and Wenbin $\mathrm{NI}^{2, \mathrm{c}}$ \\ ${ }^{1}$ School of Mechanical Engineering,NUST,Nanjing 210094,China; \\ ${ }^{2}$ School of Taizhou ,NUST, Taizhou 225300 , China \\ abigwrl@163.com, 'blbcnust@ sina.com, bignwb@163.com \\ *Corresponding author
}

\begin{abstract}
Keywords: Electro-hydraulic Servo System; Nonlinear; RBF Neural Network Supervision (RBFNNS); Integral Separation PID Control (ISPID)
\end{abstract}

\begin{abstract}
Electro-hydraulic servo control system is a nonlinear and uncertain system with time-variation parameters and external disturbance. The traditional Proportion Integration Differentiation(PID) controller can hardly control the nonlinear and time-variant systems, whereas the Radial Basis Function (RBF) controller may solve the problem under the condition of the control parameters' reasonable selection. In order to ensure the static and dynamic performance of certain electro-hydraulic servo system, an Integral Separation PID Controller (ISPID) based on RBF Neural Network Supervision (RBFNNS ) was proposed. Taking advantage of the ISPID Controller and RBFNNS, optimum control of certain electro-hydraulic servo system was achieved. The results of MATLAB simulation and the prototype tests show that the overshoot of the proposed system is $2.5 \%$, the steady state error of step response is about $0.10 \sim 0.91 \mathrm{~mm}$, and the error of prototype depth control is no more than $\pm 10 \mathrm{~mm}$. Compared with the traditional PID controller and the RBF controller, the proposed system has advantages of speedy response, smaller overshoot, high steady-state accuracy and strong robustness. It proves that the proposed control scheme is effective and suitable.
\end{abstract}

\section{Introduction}

With the advantage of fast response speed, high precision, large power volume, wide speed range, etc, Electro-hydraulic servo system has been widely used in aerospace, weapon system, etc. Compared with AC/DC motor servo system, the dynamic characteristics of electro-hydraulic servo system is more complicated, it is a typical nonlinear and time-varying system.There are many factors that cause the nonlinear of electro-hydraulic servo system, such as work dead zone of hydraulic valve, hydraulic oil compression,saturated friction, etc[1]. And its time-variation mainly shows that the changes of Viscosity-temperature characteristics, Viscous pressure characteristics, Elasticity modulus, etc, along with the changes of system load, environmental temperature.

Under the very bad conditions of variable load, strong interference and big inertia, etc, the traditional control methods can hardly realize the requirements of fast response, less overshoot and high tracking accuracy and can hardly achieve the requirements of dynamic and steady-state performance index for electro-hydraulic servo system[2,3].Additionally, for the purpose of achieving excellent control results, it is necessary to adopt valid control methods, such as Proportional integral derivative(PID) control [4,5], neural network control [6-8], fuzzy control [9-11], etc.

Nowadays, PID control is still widely used for its merits of simple structure,reliable and robust [12]. However, it is very difficult to control a nonlinear system . In [13],WANG Li-mei,DONG An-ji(2013) designed a neural network self-tuning PID controller based on RBF. The controller could weaken the hysteresis and could track the reference input, but its overshoot was too big 
Significantly. In [14], the self-adaptive PID control algorithm based on RBFNNS was adopted in the thrusting system of the double-shield TMB. Good tracking control effect was obtained. And the designed algorithm could improve the system robustness and the adaptive ability obviously . If the control parameters of the system were selected improperly, the training time would be longer. And the control parameters affected the system tracking performance directly.In $[15,16]$, the Integral Separation PID control algorithm was presented. When the system was at start, stop, or under strong interference, it could solve the problems of slow response and big overshoot effectively, which caused by PID transient integral accumulation.

In order to ensure the static and dynamic performance of certain electro-hydraulic servo system, an ISPID Controller based on RBFNNS was proposed. Making the most of ISPID Controller and RBFNNS, optimum control of certain electro-hydraulic servo system was achieved. The results of MATLAB simulation and the prototype tests show that, the designed controller in the paper is better than the traditional PID controller and RBFNNS.Compared with the traditional PID controller and the RBF controller, the proposed system has advantages of speedy response, smaller overshoot, high steady-state accuracy and strong robustness. And it can control the nonlinearity and time-variation of the electro-hydraulic servo system effectively. It proves that the proposed control scheme is effective and suitable.

\section{Certain mine sweeping plough electro-hydraulic servo system}

The principle block diagram of Certain mine sweeping plough electro-hydraulic servo system is shown in figure 1. Its working principle is that: First, the difference between the setting of eat soil depth and the practical soil depth is compared by the control computer; Second, according to the difference the corresponding control signal is calculated and passed to the servo amplifier before conversion by $\mathrm{D} / \mathrm{A}$; Then the control signal is modulated and amplified to drive the servo valve work by the servo amplifier.

The servo valve is used to control the hydraulic cylinder, so as to realize the rise and fall of the mine sweeping plough. And the mine sweeping plough weeps mines according to the setting of eat soil depth. The practical soil depth of the mine sweeping plough is measured by the shaft angle sensor, which is installed on the copying boots. After decoding by the RDC module, the decoding signal is feedback to the computer and form a closed loop control.

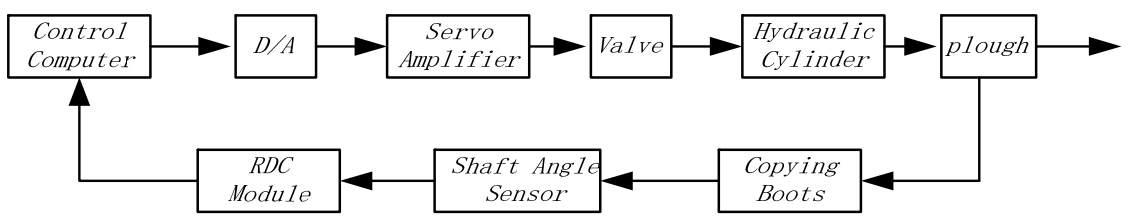

Figure 1. The principle block diagram of the electro-hydraulic servo system

\section{Integral Separation PID Controller based on RBFNNS}

\subsection{RBF Neural Network Supervision}

The RBFNNS controller is akin to a feed forward controller. The inverse model of the controlled object was established. The RBFNNS controller could adjust the online real-time weights of neural network, through learning the traditional controller's output. And in order to realize the neural network controller to replace the traditional feedback controller, the controller made the feedback control input $u_{p}(k)$ close to the value of zero. When the system confronted a larger load or disturbance, the feedback controller would be back to work.

The RBF neural network is one kind partial approaches network, it can be approaching to any continuous functions with arbitrary precision[17]. The structure of RBFNNS controller is shown in figure 2 . 


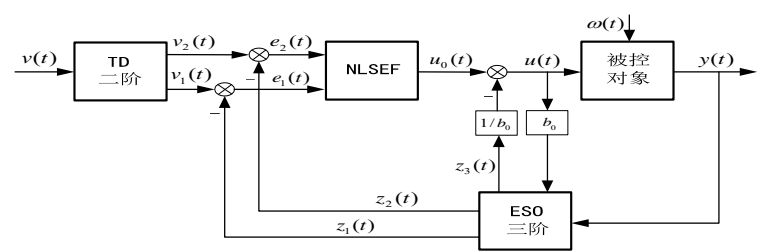

Figure 2. The structure of RBF Neural Network Supervision

In the RBF network structure, the input is $r(k)$, radial basis function vector is $H=\left[h_{1}, h_{2}, \cdots, h_{m}\right], h_{j}$ is Gaussian basis function

$$
h_{j}=\exp \left(-\frac{\left\|r(k)-C_{j}\right\|^{2}}{2 b_{j}^{2}}\right)
$$

Where $j=1,2, \cdots, m, m$ is the number of neurons in hidden layer network; $b_{j}$ is the base width parameter of the node $\mathrm{j}, b_{j}>0 ; c_{j}$ is The center vector of the node $\mathrm{j}$ network, $C_{j}=\left[c_{11}, \cdots, c_{1 m}\right]^{T}$, $B=\left[b_{1}, \cdots, b_{m}\right]^{T}$.

The weight vector of neural network is $W=\left[w_{1}, \cdots, w_{m}\right]^{T}$. The RBF network output is: $u_{n}(k)=h_{1} w_{1}+\cdots+h_{j} w_{j}+\cdots+h_{m} w_{m}$

The control law is $u(k)=u_{p}(k)+u_{n}(k)$, the performance indicators of the neural network adjustment is:

$$
E(k)=\frac{1}{2}\left[u_{n}(k)-u(k)\right]^{2}
$$

The approximation is :

$$
\frac{\partial u_{p}(k)}{\partial w_{j}(k)}=\frac{\partial u_{n}(k)}{\partial w_{i}(k)}
$$

The error caused by the approximation is compensated by weight adjustment.The gradient descent method is adopted to adjust the weights of the network.

$$
\Delta w_{j}(k)=-\eta \frac{\partial E(k)}{\partial w_{j}(k)}=-\eta\left[u_{n}(k)-u(k)\right] \cdot h_{j}(k)
$$

Where $\eta$ is learning rate.

The adjustment process of neural network weights is:

$$
W(k)=W(k-1)+\Delta W(k)+\alpha[W(k-1)-W(k-2)]
$$

Where $\alpha$ is momentum factor.

\subsection{The ISPID Controller based on RBFNNS}

The traditional PID Controller based on RBFNNS can realize the effective control of nonlinear systems. When the system selects the improper parameters or is in the case of varying load, strong interference, it can be prone to the system defects of big overshoot, long training time and even larger system oscillation at the beginning response or in the process. However the introduction of the ISPID controller based on RBFNNS is a good way to eliminate this defects. The basic idea of integral separation is: When the input has great change,or the deviation between the setting value and the actual feedback is bigger than a certain threshold value(larger overshoot will be produced at this time), Proportion regulation is not done to avoid larger overshoot in order to increase the speed of the system response. If the system is in the start-stop phase, or the setting value has great change, only Proportion and Differentiation regulation are done. And when the deviation is less than a certain value, Integration regulation returns to work for eliminating the error, and ensures the system control accuracy.The structure of the ISPID Controller based on RBFNNS is shown in figure 3 . 


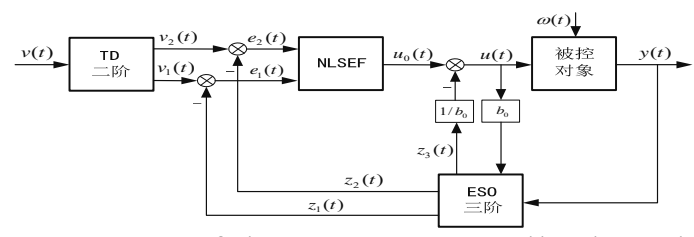

Figure 3. The structure of the ISPID Controller based on RBFNNS

The working principle of Integral separation PID controller is described as follows: (1) According to the actual situation, the artificial threshold value $\varepsilon>0$ is given; (2) When $|\operatorname{error}(k)|>\varepsilon$, the PD controller is taken to avoid larger overshoot in order to increase the speed of the system response; (3) When $|\operatorname{error}(k)| \leq \varepsilon$, the PID controller is taken to ensure the system control accuracy. the integral separation control algorithm is:

$$
\begin{aligned}
u(k) & =k_{p} \operatorname{error}(k)+\beta k_{i} \sum_{j=0}^{k} \operatorname{error}(j) \\
& +k_{d}[\operatorname{error}(k)-\operatorname{error}(k-1)] / T
\end{aligned}
$$

Where $T$ is sampling time, $\beta$ is switch parameters of integral item.

When $|\operatorname{error}(k)|>\varepsilon$, according to different segment, the further segment can be refined to sure the different $\beta$ in order to provide optimal $u_{p}(k)$ input value for RBFNNS. And it can enhance the stability and dynamic performance of the whole control system.

\section{The results of MATLAB simulation and the prototype tests}

In [18-19], the methods of mechanism modeling and intelligent modeling,etc were adopted to build the structure model of electro-hydraulic servo system for the system simulation. The system exists serious nonlinear and time-variation, so the traditional mechanism modeling method is difficult to establish accurate mathematical model. However the intelligent modeling can solve this problem well. In [20], the identification of RBF neural network was designed to meet the requirements of accuracy and could meet the needs of the on-line control. In this paper, the accurate control of electro-hydraulic servo system was achieved on the basis of the identification implementation.

In the MATLAB environment, the simulation was studied for the electro-hydraulic servo system. Through the step and sine response of the system ,the dynamic and static characteristics were compared by the traditional PID controller, the RBFNNS controller and the ISPID controller based on RBFNNS.

Figure 4 is the system step response curve. Figure 5 is the system simulation error curve. As figure 4 and figure 5 shows, under the step response, the overshoot of the ISPID controller based on RBFNNS is $2.5 \%$, but the overshoot of the traditional PID controller and the RBFNNS controller are $14.41 \%$ and $12.40 \%$ respectively. Because the system exists serious nonlinear, the steady state error of the ISPID controller based on RBFNNS is about $0.10 \sim 0.91 \mathrm{~mm}$; But the steady state error of the traditional PID controller and the RBFNNS controller are $-3.11 \sim 5.10 \mathrm{~mm}$ and-2.76 $1.52 \mathrm{~mm}$ respectively. Compared with the traditional PID controller and the RBF controller, the proposed system has advantages of speedy response, smaller overshoot, high steady-state accuracy and strong robustness.

As Figure 6 sine tracking response curve shows, the steady state error of the ISPID controller based on RBFNNS is not more than $2 \mathrm{~mm}$, but the steady state error of the traditional PID controller is more than $10 \mathrm{~mm}$ and the RBFNNS controller is only about $3.5 \mathrm{~mm}$. by comparing, the ISPID controller based on RBFNNS has better dynamic tracking performance. 

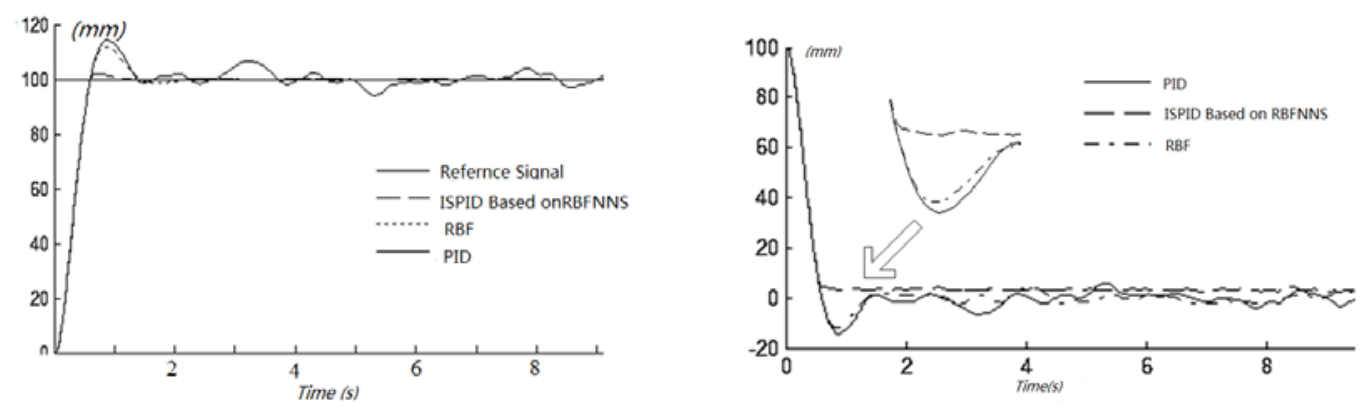

Figure 4. The system step response curve Figure 5. The system simulation error curve
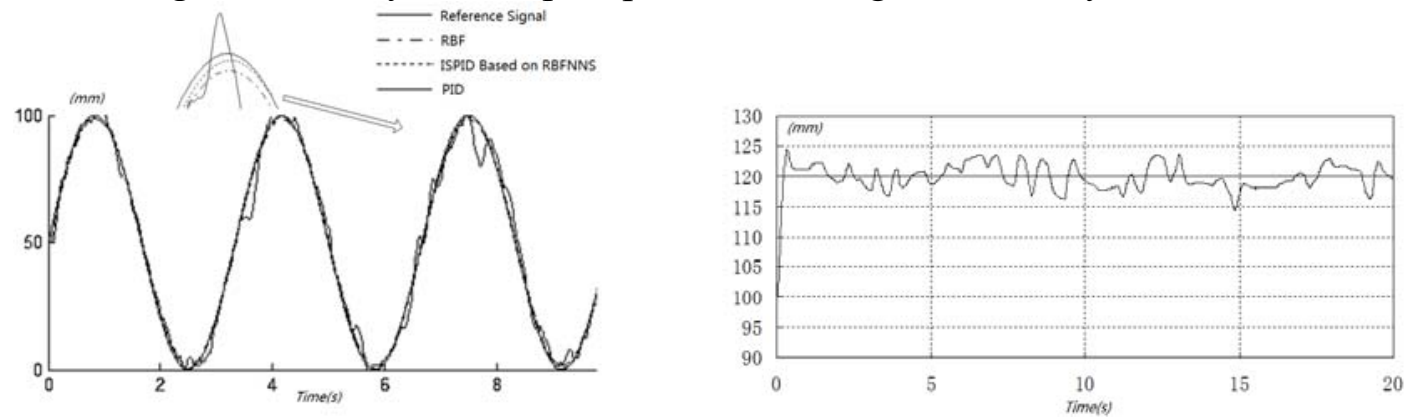

Figure 6. Sine tracking response curve Figure 7. The eat soil depth control curve

\section{Experimental research}

The depth control technical indicators of Certain Electro-hydraulic Servo System shall meet : (1) With the function of automatic control mine sweeping, the mine sweeping plough should stop work when the cancel key is pressed during sweeping process or sweeping end. (2) The vehicle speed is not more than $5 \mathrm{~km} / \mathrm{h}$, the depth error is no more than $\pm 10 \mathrm{~mm}$.

The setting eat soil depth was $120 \mathrm{~mm}$. The prototype tests showed that when the setting eat soil depth was $120 \mathrm{~mm}$, the error of prototype depth control was no more than $\pm 10 \mathrm{~mm}$. It proved that the proposed control scheme meets the requirements of the technical indicators.

\section{Conclusion}

In this paper, an ISPID Controller based on RBFNNS was studied in order to solve time-variation and nonlinearity of Certain Electro-hydraulic Servo System. The results of MATLAB simulation and the prototype tests showed that the proposed control scheme had advantages of speedy response, smaller overshoot, and strong robustness. Compared with the traditional PID controller and the RBF controller, the designed controller in the paper has better dynamic and steady-state performance. And it can meet the technical requirements of Certain Electro-hydraulic Servo System .

\section{Reference}

[1] Tanasak Samakwong, Wudhichai Assawinchaichote.PID Controller Design for Electro-hydraulic Servo Valve System with Genetic Algorithm[J] . Procedia Computer Science, Volum 86, 2016, Pages 91 94.

[2] Gao Qiang, Jin Yong, Wang Li, etal.Modeling of electro-hydraulic position servo systems of pump-controlled cylinder[J]. Binggong Xuebao/Acta Armamentarii, 2011, 32(8):950 956.

[3] WANG Rong-lin, FAN Huan-ying, etc.Active Disturbances Rejection Control of Certain Electro-hydraulic Servo System Based on Neural Network[[J]. Coal Mine Machinery, 2013, 34 (10) : 73 76.

[4] S. Centin, A.V. Akkaya, Simulation and hybrid fuzzy-PID control for positioning of a hydraulic system, Nonlinear Dyn. 61 (2010) 465 476. 
[5] J.M. Zheng, S.D. Zhao, S.G. Wei, Application of self-tuning fuzzy PID controller for a SRM direct drive volume control hydraulic press[J]. Control Eng. Pract. 17 (2009) 1398 1404.

[6] C.L. Wu, et al., Methods to improve neural network performance in daily flows prediction[J]. Hydrol. 372 (2009) 80 93.

[7] R. Taormina, et al., Artificial neural network simulation of hourly groundwater levels in a coastal aquifer system of the Venice lagoon[J]. Eng. Appl. Artif. Intell. 25 (2012) 1670 1676.

[8] C.Y. Jia, X.Y. Shan, Y.C. Cui, T. Bai, F.J. Cui, Modeling and simulation of hydraulic roll bending system based on CMAC neural network and PID coupling control strategy[J]. Iron Steel Res. Int. 20 (10) (2013) 17 22.

[9] Z.H. Liu, Q.H. Gao, H.L. Niu, The research on the position control of the hydraulic cylinder based on the compound algorithm of fuzzy \& feedforward-feedback[J]. Sens. Transducers 162 (1) (2014) 314 324.

[10] H.M. Yousif, K. Ganesh, Interval type-2 fuzzy position control of electro-hydraulic actuated robotic excavator[J]. Int. J. Min. Sci. Technol. 22 (2012) 437 445.

[11]M. Kalyoncu, M. Haydim, Mathematical modeling and fuzzy logic based position control of an electrohydraulic servosystem with internal leakage[J]. Mechatronics 19 (6) (2009) 847 858.

[12] Karam M. Elbayomy, Jiao Zongxia, Zhang Huaqing.PID Controller Optimization by GA and Its Performances on the Electro-hydraulic Servo Control System[J]. Chinese Journal of Aeronautics 21(2008) 378 384.

[13]WANG Li-mei, DONG An-ji.Based On RBF Neural Network Self-Tuning PID Control of Giant Magnetostrictive Actuator[J]. Modular Machine Tool \& Automatic Manufacturing, ,2013 (5) : $76 \sim 79$.

[14]XU Li-ping, HOU Kun-zhou,etc.Simulation study on PID double-shield thrusting system based on RBFNN[J]. Mining \& Processing Equipment, 2013,38 (3) : 4 8

[15] Zhu Shi-lin,Pan Haipeng.Realization of Integral Separation PID Algorithm in variable Frequency SpeedRegulationsystem[J]. ElectricalAutomation,2010,32(1):33 35.

[16] Huang Xiang-yuan.Tension Controller with Integral-separation PID Algorithm[J]. Industrial Control Computer,2011,24(5):37 39.

[17] Han Me Kim, Sung Hwan Park, Ji Min Lee, et al.A robust control of electro hydrostatic actuator using the adaptive back-stepping scheme and fuzzy neural networks[J].International Journal of Precision Engineering and Manufacturing,2010,11 (4):227 236.

[18]WuXiao-xiao,Chen,Ji-lin ,Wang,Li.ModelingandSimulationofElectrohydraulicServoSystemBas edonRBFNeuralNetworkTrainedbyaClusteringandGradientHybridAlgorithm[J].ElectricalAutomatio n,2011,33(1):20 22.

[19]XING Zong-yi, ZHANG Yuan, HOU Yuan-long,etc.Modeling of Electrohydraulic System and Its Application [J].Journal of System Simulation,2011, 6(3):1119 1125.

[20] QIAN Jin,CHEN Jilin. Modeling of the Electrohydraulic System of a Certain Demolition Mine Sweeper Based on Neural Network[J].Machine Tool \& Hydraulics, 2011,23(12):134 136. 